\title{
Economical and Safe Design for Low-Traffic Long-Roads Illumination Control System by Using Image Recognition Technique
}

\author{
Muhammad M. A. S. Mahmoud*, Leyla Muradkhanli \\ Process Automation Engineering Department, Baku Higher Oil School, Baku, Azerbaijan \\ Email address: \\ mmanar@yahoo.com (M. M. A. S. Mahmoud), leyla.muradkhanli@socar.az (L. M. Name) \\ ${ }^{*}$ Corresponding author
}

\section{To cite this article:}

Muhammad M. A. S. Mahmoud, Leyla Muradkhanli Name. Economical and Safe Design for Low-Traffic Long-Roads Illumination Control System by Using Image Recognition Technique. Journal of Electrical and Electronic Engineering. Vol. 8, No. 5, 2020 , pp. 117-126. doi: $10.11648 /$ j.jeee.20200805.11

Received: October 14, 2020; Accepted: October 23, 2020; Published: November 11, 2020

\begin{abstract}
The paper covers analysis and investigation of lighting automation system in low traffic roads. The main objective is to provide optimal solution between expensive safe design utilizes continuous lighting at night for the complete road, or sacrifice the safety to minimize the cost of energy consumption by relying on using vehicles lighting in low traffic road designed without lighting systems. Each of these two scenarios is extremely significant issue and contradicting to each other from economic point of view. By taking into account both of these factors, smart lighting control system is proposed using Image Recognition Technique. In this proposal, the road is sectionalized into zones. By using motion sensors and Infra-Red cameras distributed and installed in each zone, any moving object can be detected and its image can be captured and analyzed using Image Recognition Technique to check whether the object is a vehicle or not. Matlab code is written and tested using different images to validate the code output. In case a vehicle is detected, the control system of the road lighting illuminates only the zone that the vehicle passes through. Economic analysis is provided in this paper to support the value of using this design of lighting control system. "Saving Norm" of $\$ 1,171.19 / \mathrm{km} /$ Year is calculated for the proposed system. This "Saving Norm" is a good index to supports project management for both project decision makers and for cash-flow controllers.
\end{abstract}

Keywords: Road Lighting Control, Road Lighting Automation, Vehicle Image Recognition, Smart Grid, Power Management, Low Traffic Roads

\section{Introduction}

Various road classifications are existed in terms of traffic. Principal arterials, minor arterials, rural collectors, local roads and very low-volume roads, and the last is what our concern in this paper. Statistically, for low-traffic roads the flow rate of the vehicles is assumed to be 400 vehicles per day [1]. In low these roads, even simple lighting system is not installed mostly, and authorities rely on vehicle lights put human life and valuable product transported under the risk. The main reason of non-lighting system is to save the energy. However, fully lightened roads cause wastage of electricity as one vehicles may appear every three or four hours and even more during the night time. Each of these two scenarios is extremely significant issue.
Several researchers did some projects and published their work related to this topic, however, none of them has considered the lighting automation system on low traffic road. Articles are mainly related to smart or automated street lighting systems. In the following paragraphs, several researches' results is discussed, and main points are drawn into attention.

P. V. K. Bhangdiya suggests to use two sensors in order to consume less power with maximized efficiency of a system is proposed. Light Dependent Resistor (LDR) sensor is utilized to measure the sun light intensity to control the switching action of LED streetlights, and Passive Infrared Resistor (PIR) motion sensor is used for changing the intensity of LED light when there is no motion of object at mid-night on street then all the streetlights are dimmed [2]. However, Noor Lina Ramli 
indicates that LDR and PIR sensor are used for same purpose, but without dimming the light, just switched on or off [3]. Sindhu. A. M worked on this topic using Infrared Resistor (IR) sensors which measure the heat of an object as well as detects the motion, in contrast to what previous researchers did [4]. They developed the system using Arduino Uno R3 while Ms. M. Kokilavani, achieved the same by Raspberry Pi 3 micro controller [5].

Faiz Ansari offered Zigbee Based Smart Street Light Control System Using LabVIEW. Here, movement is detected by motion sensors, communication between lights is enabled by Zigbee technology. So, when a passer-by is detected by a motion sensor, it will communicate this to neighboring streetlights, which will brighten so that people are always surrounded by a safe circle of light [6].

Aman Kumar Akash developed Intelligent Street Lighting System Using GSM technology. The aim is to achieve the energy saving and autonomous operation on economical affordable for the streets by installing chips on the lights. These chips consist of a micro-controller along with various sensors like $\mathrm{CO}_{2}$ sensor, fog sensor, light intensity sensor, noise sensor and GSM modules for wireless data transmission and reception between concentrator and PC. The emissions in the atmospheres would be detected along with the consumption of energy and any theft of electricity [7].

Automatic street-light control system using wireless sensor networks is proposed by. D. SA. S. Rajasri. The system contains lamp station and base station. Each lamp station consists of Arduino Uno board as microcontroller, PIR sensor, emergency switch, LDR sensor, nRF24L01 transceiver, ultrasonic sensor, relay, LED light and a solar panel as energy source. The base station consists of Raspberry Pi as processor, nRF24L01 transceiver, and a GSM module. The automatic streetlight turns on under three conditions. Firstly, when PIR sensor detects a human or a moving object vehicle LED light is turned on. Secondly, an ultrasonic sensor is used to detect distance objects and turn on the light accordingly. Lastly, a switch is included for manual operation in case of maintenance work. The LDR sensor is included to measure the light intensity for identification of the day and night. There nRF24L01 wireless transceiver transmits the sensor information and the light status to the Raspberry web server to upload on the web page. Also, it receives commands sent from the web page to turn on or off the light at a particular node. The entire system is powered using solar cells making it more energy efficient [8].

Muhammad M. A. S. Mahmoud tried to solve the problem of high operational cost of low traffic light that use HPS lighting by using LED light fitting instead of HPS luminaries [9].

Many real projects have been done on this area, but few of them are related to this topic exactly. Most of them consider street, campus, parking, park or any small area lighting system. The rest of them is devoted to road light and control systems. Some of them will be analysed, discussed and compared [10, $11]$.

From the above literature review, firstly, all systems mentioned above used LDR sensor to sense night-time to operate the control system itself. In the system prosed in this paper, the same day/night sensor idea is also use to know exact hours of night-time or any dark time during the day time due to heavy cloud or any other reasons.

Secondly, all systems above have used motion sensors to detect the object movement whatever this object is, and hence control the lights in terms of switching ON/OFF or dimming. IR sensors and PIR sensor were the preferred sensors used to detect the object. These type of sensors detect mainly warm object and their movement. But, for the suggested system in this paper that need to be used for low traffic road, movement of only vehicle is needed to be recognised and hence switch on the light or dim them. The proposed system need to be designed to avoid any other motion such as animals, birds, or other objects which may be detected by IR or PIR sensors as this unnecessary detection of motion can cause unjustified energy consumption. Therefore, it is needed to give new approach to tackle with such problems. New approach could be to add the night vision smart camera to the system in order to recognize only the vehicles among all other objects that the camera detects.

Thirdly, some systems control the illumination by measuring the intensity of the objects movement and change the dimming of the lights accordingly. But for illumination system of low traffic roads, the intensity of the vehicles is continuously very low, and hence dimming technique is not effective solution.

Fourth, using LED light continuously operate during the night for low traffic roads can reduce the cost of illuminating the road compared with any other HID lighting, but still this is not best solution because the utilization of this system by this operational philosophy is not an efficient utilization because most of the time the light is ON unnecessary

Fifth, in general, previous researches have been done on lighting automation system for the roads which serve both pedestrians and vehicles. But, this paper tries to design automation lighting system for long road with low traffic, where no need to switch on the lights for movement of any object except the vehicles

In this paper, efficient, safe and cost effective solution to design automated lighting system suitable for long roads with low-traffic is provided. In section 2, description of the entire system design is discussed. Section 3 illustrates the methodology and the programing of vehicles recognition using camera images. Section 4 provides economic analysis for the proposed system. Conclusion is given in Section 5 .

\section{System Design Description}

Lighting automation system in low traffic roads is intended to implement in the illuminated roads. It is supposed to have source power supply, feeder pillar with controller, light poles with day/night sensor. Such conventional system can be upgraded by new automated system. The methodology of lighting automation system in low traffic roads is achieved by applying the moving object recognition technique using 
cameras. Firstly, the road is sectionalized into several zones. Each zone depends on how much distance is existed between two feeder pillars, typically 400 meters. So, light poles in each zone will be switch on/off together. It means that each zone will have its feeder pillar (control panel) with controller, day/night sensor, motion sensor, and camera. Night vision cameras are installed on the road in such way to detect the vehicle arrival-to and departure-from each zone. The controller is designed to illuminate only the zones in which the vehicle is detected. The type and span of the zone are calculated based on the road design considering straight spans and roundabout.

\subsection{Lighting Control Conceptual Design}

The control scheme of the automatic lighting system is illustrated in Figure 1. Day/night switch detects darkness status to start the controller and hence motion sensor and night vision cameras. Now, let us consider that there are two adjacent zones (Zone $\mathrm{N}$ ) and (Zone $\mathrm{N}+1$ ), and vehicle enters to Zone $(\mathrm{N}+1)$. Mainly, day/night sensor and motion sensors of (Zone $\mathrm{N}+1)$ need to be installed before the camera of (Zone $\mathrm{N}+1$ ), while camera of (Zone $\mathrm{N}+1$ ) need to be installed in (Zone $\mathrm{N}$ ) near to the end. This is because camera need to start capture the moving objects images only after motion sensor detects any object in advance and sends the signal to the camera to start operation, and hence the controller takes the proper decision for switch the light of (Zone $\mathrm{N}+1)$ before the object enter the zone.

For that, camera is installed on a light pole about $80 \mathrm{~m}$ before each zone. This distance provides approximately 2 seconds for data processing and control assuming maximum speed is approximately $60 \mathrm{~km} /$ hour. Figure 2 illustrates the installation location of (Zone $\mathrm{N}+1$ ) camera, day/night sensor and motion sensors in (Zone $\mathrm{N}$ ).

The software in the controller extracts the image from the camera and analyze it to determine whether the object is vehicle or not. If the object is not a vehicle, no action is taken by controller. In case the object is vehicle, signal shall be sent to Zone $\mathrm{N}+1$ lighting feeder pillar to switch on light of Zone $\mathrm{N}+1$ Simultaneously signal shall be sent to Zone $\mathrm{N}$ controller to switch off lightning system of Zone.

\subsection{Switching on/off Lighting System for a Zone}

As we explained above, each Zone has its own lighting control system consists of Day/night switch, motion sensor, night vision camera, controller and feeder pillar.

When the controller of any zone detect "vehicles" the digital counter inside this controller counts the number of these detected vehicle (Nin). In the same time, the same controller receives from the digital counter inside the controller of next Zone updated number of the vehicle interring the next zone (Nout). The communication between the controllers can be achieved by Power Line Telecommunications method. or RS-485 cable. If the difference between the these to numbers (Nin- Nout) is zero, this means that no vehicles exist in this zone, and the controller switches "Off" the light. As long as (Nin- Nout) is not zero, the light of the zone will be kept "On". This methodology insures that the lighting system for any zone is kept "On" if any vehicle (s) still in that zone for any reason such as accident, maintenance or temporary parking. Also, This methodology insures that the lighting system of the zone free of any vehicle is "OFF".

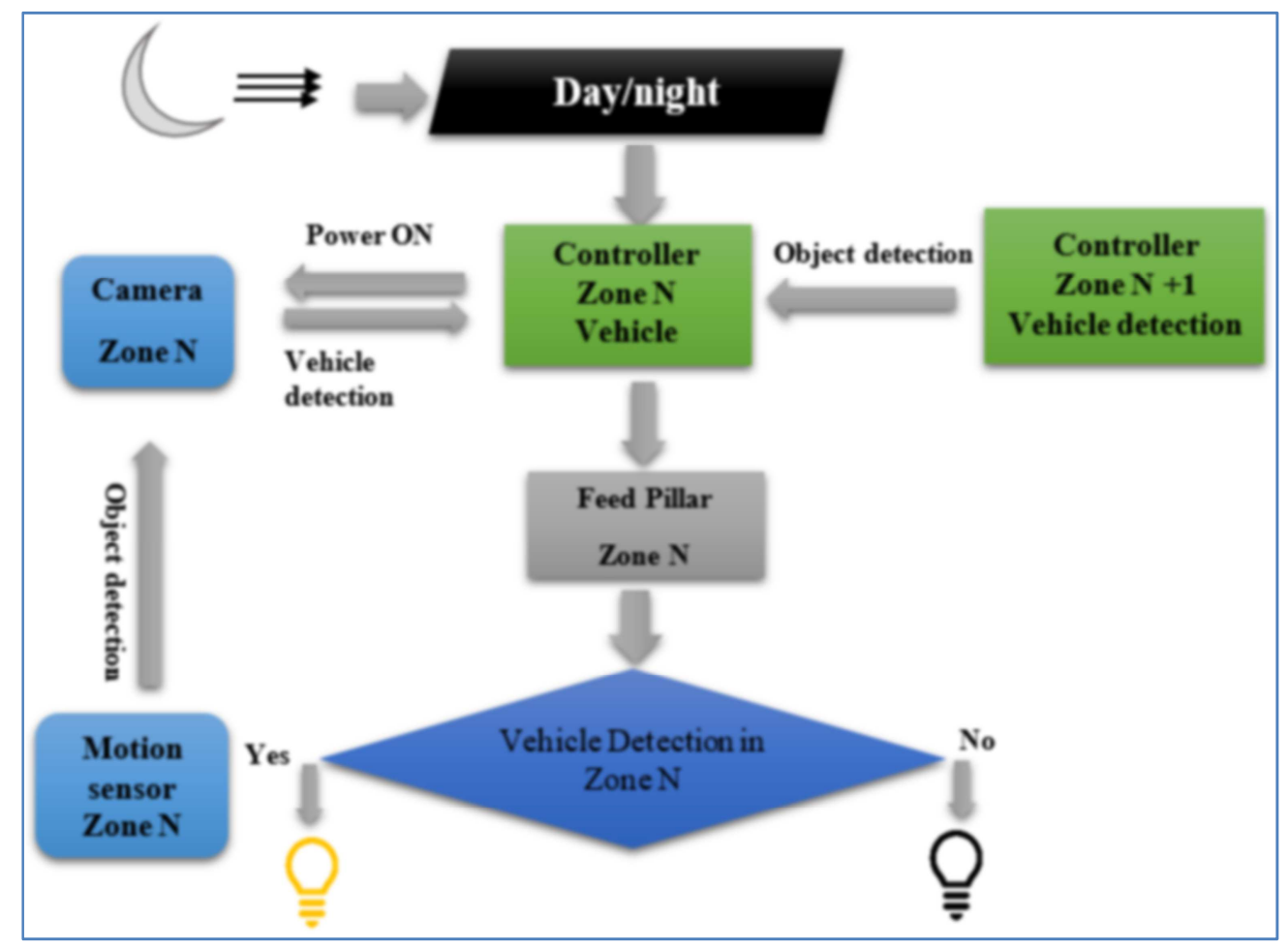

Figure 1. Automatic lighting system schematic. 


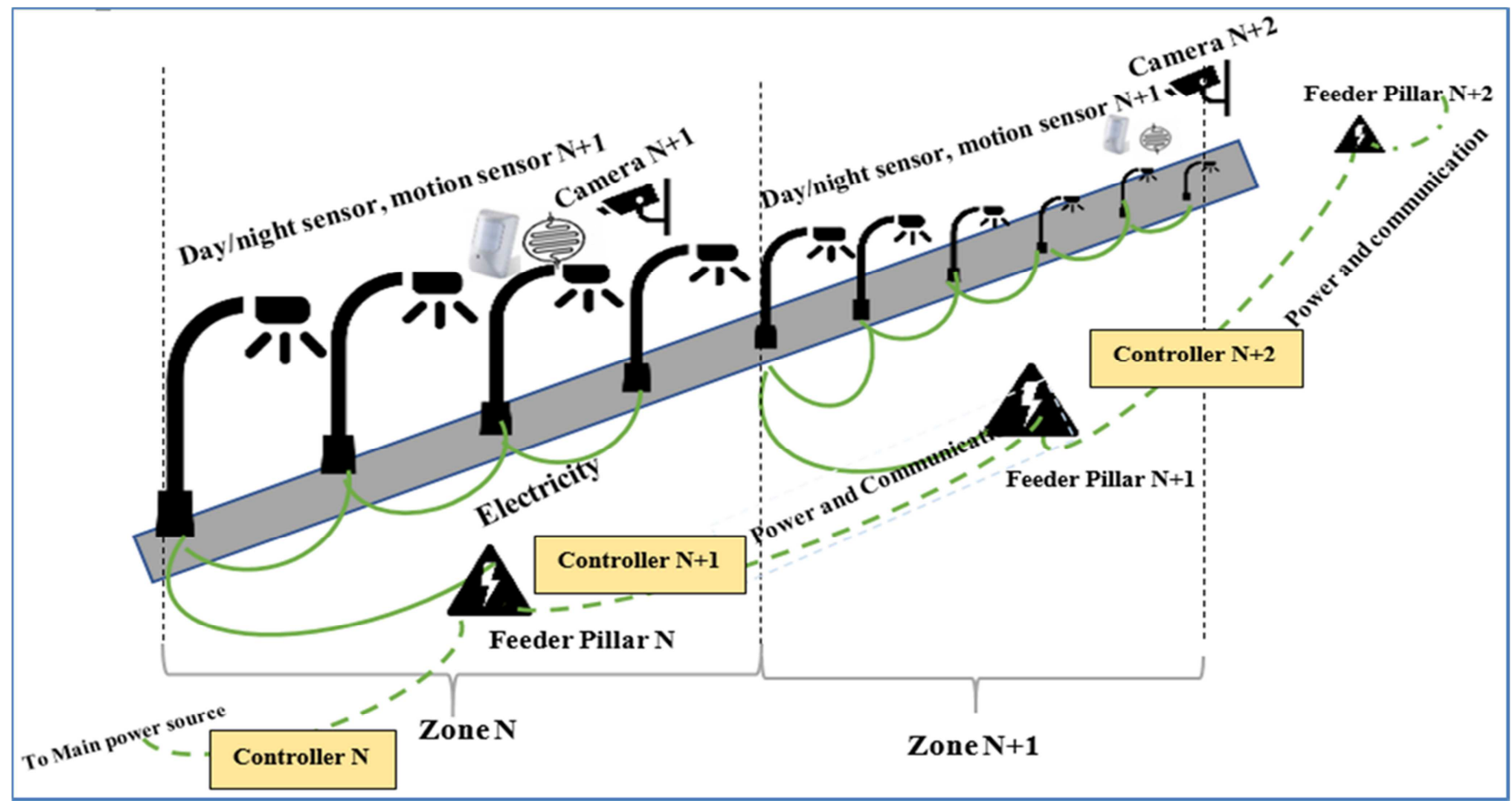

Figure 2. Zone Definition.

In Figure 3, flow chart for two consequent lighting system control logic is illustrated.

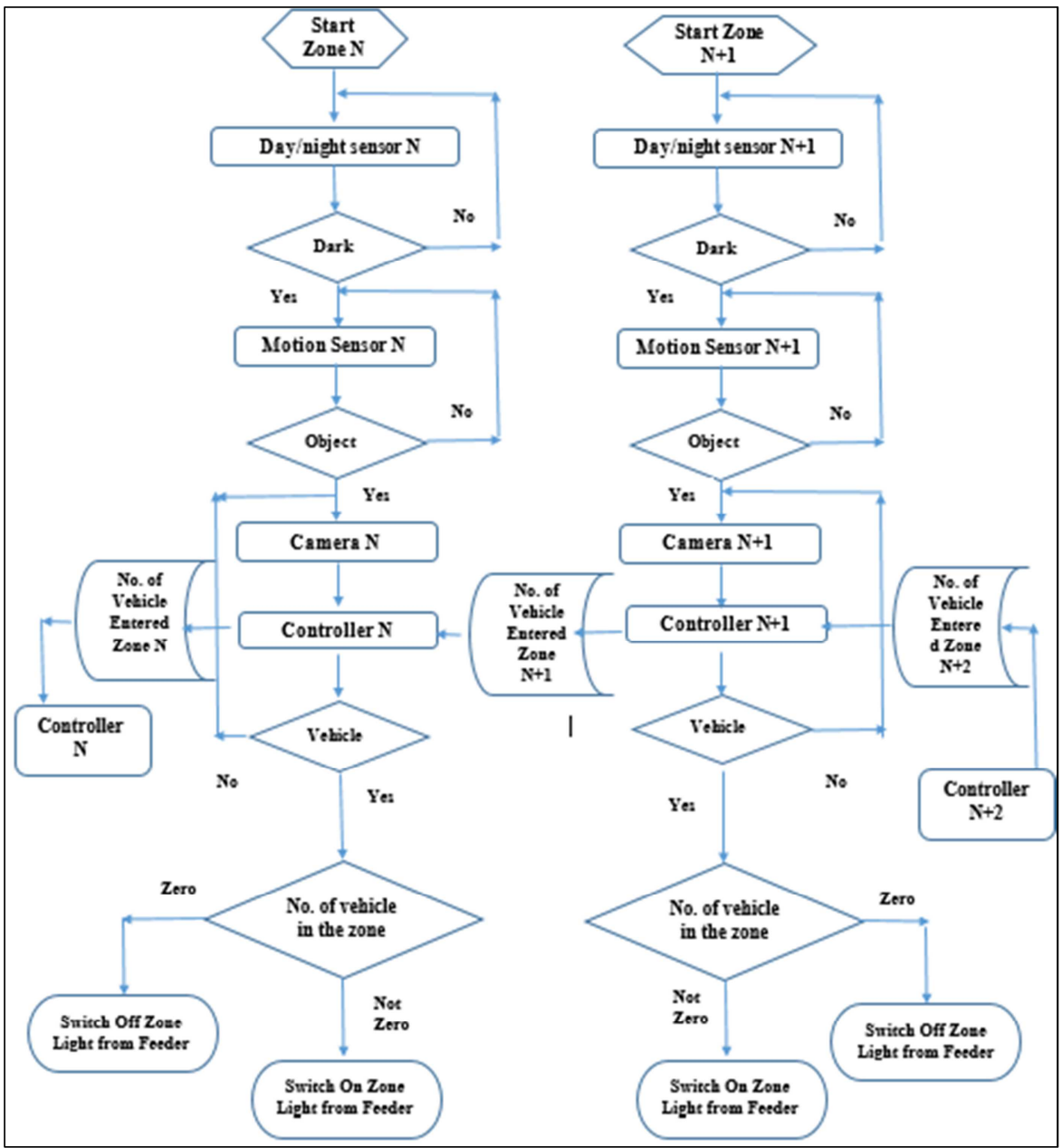

Figure 3. Control flow chart for Zone $N$ and Zone $N+1$ lighting system. 


\section{Vehicle Image Recognizing}

\subsection{Survey}

Several researches are done to recognize the vehicle at night based on vehicle lamp detection $[13,14]$. This method will not work in case the vehicle lights are switches off for any reason. Another researchs are carried out to detect the information in vehicle number-plate using artificial intelligent methods [15, 16]. However, using arterial intelligent method is time consuming and not useful for the application of this paper. In this paper, recognition of the number-plate rectangular frame is simple method and more than enough to confirm that the moving object is "Vehicle".

\subsection{Methodology}

The process of detection of vehicle number-plate consists of the following steps: capture of image, pre-processing, plate region extraction (Figure 4).

\subsubsection{Capture of Image}

In this step, the image is captured by electronic devices such as infrared digital camera or any other camera suitable for night time. The image captured is stored in JPEG format. After that the captured image is converted into gray scale image.

\subsubsection{Pre-processing}

The next step after capturing the image is the pre-processing of the image. When the image is captured a lot of noises present in the image. Reducing the noises from the image are required to obtain an accurate result.

The RGB image is then converted into a gray scale image for easy analysis as it consists of only two color channels.

The aim of this pre-processing is to improve the quality of the image. Image enhancement techniques are used in this step. Image enhancement techniques consists process of sharpening the edges of image, contrast manipulation, reducing noise, color image processing and image segmentation.

\subsubsection{Plate Region Extraction}

The most important stage is the extraction of number-plate from eroded image significantly. The extraction of number-plate can be done by using image segmentation method. Mathematical morphology is used to detect the region of interest and Sobel operator are used to calculate the threshold value.

In general, any vehicle has its own number-plate which is always in rectangular shape consists characters. Accordingly, the basic approach in the detection of a vehicle is to recognize its number-plate which is mainly frame with characters (Numbers and letters). So, it is necessary to detect two criteria: the edges of the rectangular plate and there are characters within the rectangular.

A morphology based approach for detection number-plates is used. Our proposed method applies basic mathematical morphology operations like dilation and erosion.

The software model using the image processing technology is designed. The programs are implemented in MATLAB. The algorithm is divided into following parts: capture image, pre-processing, plate region extraction, characters recognition.

\subsection{MATLAB Code for Number-plate Recognition}

The following MATLAB code is written to implement the above mentioned parts:

Image capturing from camera

$\%$ Read Image

Input_image = imread('Car.jpg');

RGB to gray scale

$\%$ Convert the truecolor RGB image to the grayscale image

$\mathrm{I}=$ rgb2gray(Input_image);

The following steps are used:

Image capturing from camera

$\%$ Read Image

Input_image $=$ imread('Car.jpg');

RGB to gray scale

$\%$ Convert the truecolor RGB image to the grayscale image

$\mathrm{I}=$ rgb2gray(Input_image);

Edge detection

$\%$ Sobel Operator Mask

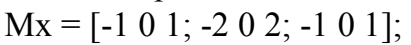

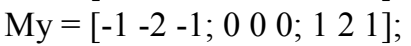

$\%$ Sobel Masking for filtering image

$\mathrm{S}=$ imfilter(I, Mx,'replicate');

Vertical and Horizontal Dilation

$\%$ Vertical Dilation

Dy = strel('rectangle', [80,4]);

Iy = imdilate(M,Dy);

Iy = imfill(Iy,'holes');

$\%$ Horizontal Dilation

Dx = strel('rectangle', [4,80]);

$\mathrm{Ix}=$ imdilate(M,Dx);

Ix = imfill(Ix,'holes');

$\%$ Joint Places

$\mathrm{JP}=\mathrm{Ix} .{ }^{*} \mathrm{Iy}$;

Dy $=$ strel('rectangle', $[4,30])$;

ID = imdilate(JP,Dy);

ID = imfill(ID,'holes');

Erosion

The process of erosion reduces removing unwanted details from a binary image.

$\%$ Erosion

$\mathrm{E}=$ strel('line',50,0);

$\mathrm{IE}=$ imerode(ID,E);

Filtering of digits

By filtering, the unwanted substances or noise can be removed or filtered out that is not a character or digits. Small objects or connected components should be removed and then the frame line that is connected to the digits should be identified and separated.

bwareaopen (Image Processing Toolbox) is applied for 
removing all the connected components from the binary image that have value less than $P$ pixels.

image $=$ bwareaopen(image, $\min ($ numberofpixel, 100));

Stats $=$ regionprops $(\mathrm{L}$, properties $)$ is applied for measuring set of properties for each labeled region in the label matrix L. stats $=$ regionprops (image 2 ,'all');

Detect plate from image

\subsection{Program Validation Process}

The validation of the of the number-plate recognition program, and hence the detection of vehicle, is done by two tests.

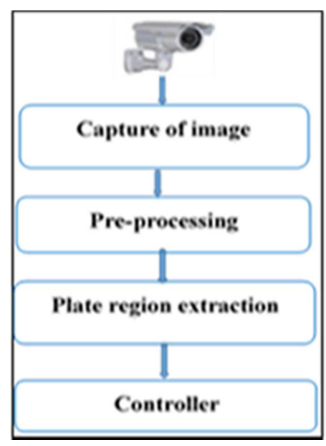

Figure 4. Vehicle Recognition Flowchart.

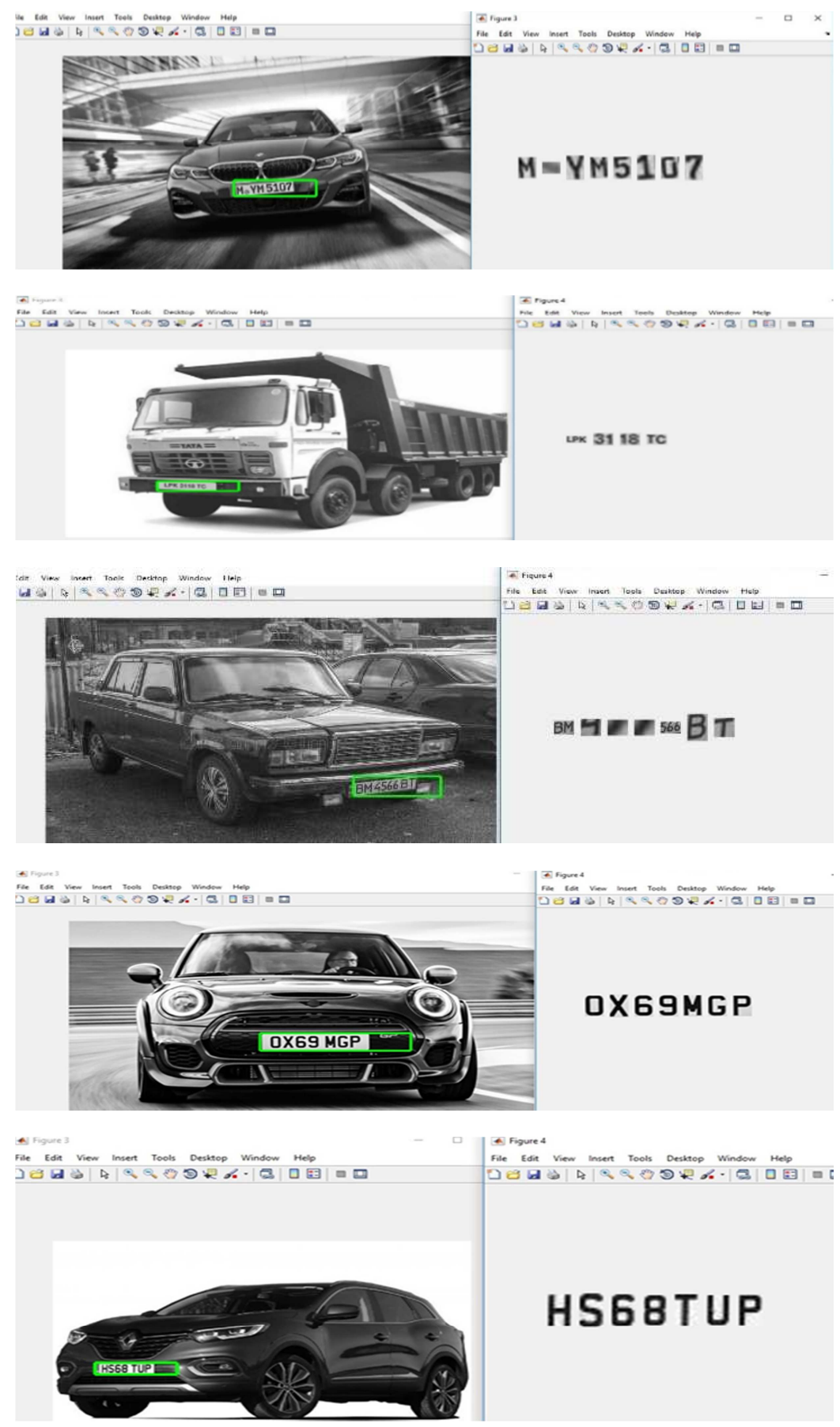




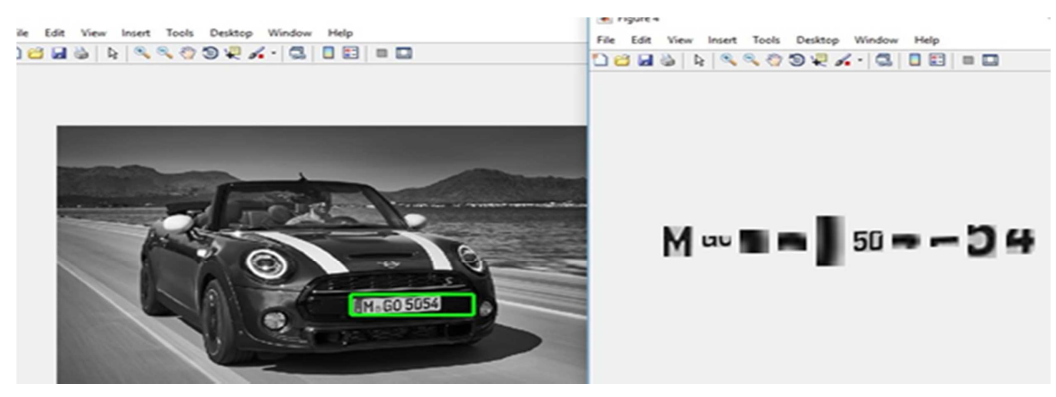

Figure 5. The results for objects with Number-plate.

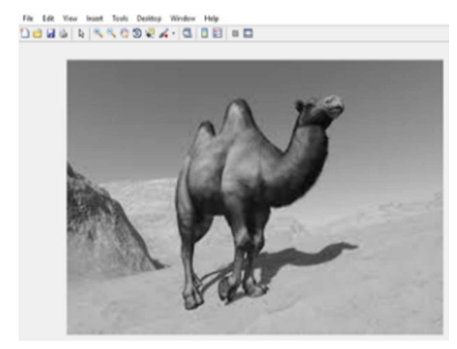

\subsubsection{Number-plate Recognized}

In this first test it needs to insure that the program recognizes any object, that is captured by the camera, has number plat. Therefore, the test is carried out to detect the number plat for different vehicle models and types with different orientations. The test result is illustrated in Figure 5. The program succeeded to detect the number-plate as rectangular frame include characters. It is worth to highlight here that it is not part of the program function to "read" the number-plate.

\subsubsection{No Number-plate Recognized}

The objective of the second test is to ensure that for any object that doesn't have number plat, the program shall detect no number-plate. The test is done using four images for different objects consist of peoples and animals (Camels and dog). The program also succeeded to detect no number-plate.

\subsection{Object Recognition in the Road}

Any moving object enters any zone of the road shall be subject to two steps of recognition process: the first recognition process is by the motion sensor which detects that there is a moving object leaving the zone (serves-zone) and enters the next zone. The second recognition process is carried out by the image processing software that detects the moving objects which has rectangular plate with characters (Vehicle). If the two condition is satisfied simultaneously, the intelligent lighting system puts $\mathrm{ON}$ the road lighting of the next zoon (vehicle entering zoon) and switch off the lighting of the service-zoon after short time delay (vehicle leaving zoon).

\section{Economic Analysis}

The following comprehensive economic study is carried out to estimate the financial benefits of using the proposed lighting automation system for the low traffic roads. The Study has considered the Direct Benefit and Indirect Benefits
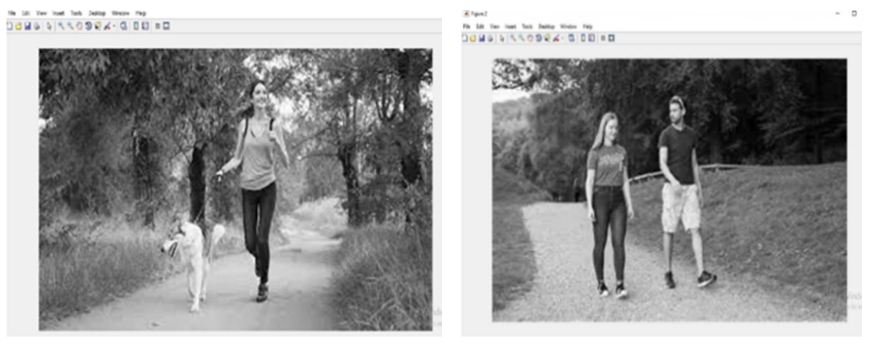

[12] in order to evaluate the entire economic value of the system:

In Direct Benefits, calculation for "New system cost", "Power consumption cost" and "Maintenance cost" are calculated based on available budgetary prices in internet. References are given hereinafter.

In Indirect Benefits, two benefits are considered: First benefit is the gas sales opportunity that will be gained from the reduction of the power consumption in case LED light is used. Natural gas valued using the wholesale price of \$4.618/MMBtu based on US Energy Information Administration Henry Hub/NYMEX futures prices; Equivalent energy rate of $5.6 \phi / \mathrm{kWhr}$ is used to value the energy produced over 10 years, assuming $1 \%$ annual escalation factor and Euro to USD exchange rate of 1.2. Accordingly,

Annual Natural Gas Sale Opportunity $=1.2 \times 0.056 \times \Delta \mathrm{kWhr} \$$

Where $\Delta \mathrm{kWhr}$ is the reduction in the power consumption.

However, the second benefit is the cost saving due to the reduction of the $\mathrm{CO}_{2}$ emission, and hence less pollution. Carbon credits based on current market is 6 euro/ton. Where, $\mathrm{CO}_{2}$ emission is considered to be $0.83 \mathrm{~kg} / \mathrm{kWh}$. Assuming Euro to USD exchange rate of 1.2 , the annual saving in pollution reduction can be calculated as following:

$$
\text { Annual Saving in Polution }=\frac{0.83 \times \Delta \mathrm{kWhr} \times 6 \times 1.2}{1000} \$
$$

Assuming for low traffic; the vehicle flow is 400 vehicles per day [1], vehicle speed is $60 \mathrm{~km} /$ hour, zone distance is 400 meter, lighting pole span is 40 meter, LED fixture consumption per pole is 75 Watts [17] and Azerbaijan electricity tariffs is $0.09 \mathrm{AZN}(0.053 \$)$ per $\mathrm{kWh}[18]$.

From the above assumptions, flow rate of the vehicle can be calculated to be 17 vehicles per hour. Considering worst road operation scenario, at which the 17 vehicles are driven with 
constant speed of $60 \mathrm{~km} /$ hour and equal distances from each other, it is obvious to conclude that one vehicle shall enter the first zone each 212 seconds and leaving the zone (400 meter) after approximately 24 seconds. Accordingly, the zone lighting fixtures shall be switched on for 29 seconds and switched of for 183 second approximately. From that, the percentage saving in power consumption using the proposed controller compared with the power consumption when road is illuminated continuously during the night is approximately $183 \times 100 / 212=86 \%$ saving.

Considering $4 \mathrm{~km}$ low traffic road operating for typically 50 years, Direct benefits and Indirect benefits can be calculated as following:

\subsection{Direct Benefits}

\subsubsection{Initial Cost of the New Control System}

Considering the cost of; camera (approximate number), day/night sensor, motion sensor, controller (simplest version), signal transmission between zones by RS-485 network, and installation (lamp i manpower, crane, dumping etc...), Table 1 can be obtained. The table illustrates that approximately $\$ 26,662.88$ is needed to provide the proposed automation lighting system for $4 \mathrm{~km}[12,19,20]$.

\subsubsection{Energy Saving}

Table 2 illustrates the comparison of energy consumption between using the proposed automation lighting system versus conventional system which operates all night, considering that both systems utilize LED fixtures with 75-Watt as minimum consumption for the conventional system. The table shows reduction in the power consumption of $86.31 \%$. This reduces drastically the electrical fault probability in the lighting electrical circuits [21, 22].

\subsubsection{Saving in Maintenance Cost}

Table 3 indicates the maintenance cost saving (in terms of light fixture) such as lamp, manpower, crane, etc. for 50 years' operation of the proposed automation lighting system and the conventional system [12].

Table 1. Initial investment.

\begin{tabular}{|c|c|c|c|}
\hline S. No & Definition (in 4 km) & With controller & Without Controller \\
\hline 1 & Total Quantity of LED & 100 & 100 \\
\hline 2 & Quantity of Day/Night sensor, Motion sensor, Camera \& Controller & 10 & 0 \\
\hline 3 & Unit price for Day/Night sensor, Motion sensor, Camera \& Controller including maintenance & $\$ 107.40$ & $\$ 0$ \\
\hline 4 & Total cost for item 3 & $\$ 1,074.00$ & $\$ 0$ \\
\hline 5 & Signal transmission between zones & $\$ 14,698.88$ & $\$ 0$ \\
\hline 6 & Total Cost of Installation & $\$ 10,890.00$ & $\$ 0$ \\
\hline $\mathrm{a}$ & Initial Investment & $\$ 26,662.88$ & $\$ 0$ \\
\hline
\end{tabular}

Table 2. Energy saving.

\begin{tabular}{|c|c|c|c|}
\hline S. No & Description & With Controller & Without Controller \\
\hline 1 & Wattage per fixture (Watt) & 75 & 75 \\
\hline 2 & № fixtures in $4 \mathrm{~km}$ & 100 & 100 \\
\hline 3 & Total power Consumed (Watt) & 7500 & 7500 \\
\hline 4 & Operating hours (hour) per day & 1.643 & 12 \\
\hline 5 & Daily operating cycle $\%$ & $6.8458 \%$ & $50 \%$ \\
\hline 6 & Operating hours (hour) in 50 Years & 29990.83 & 219000 \\
\hline 7 & Power consumed per day (kWh) & 12.325 & 90 \\
\hline 9 & Total Cost for per day $(\$)$ & 0.65 & 4.77 \\
\hline 10 & Total Cost in 50 years $(\$)$ & $11,921.36$ & $87,052.50$ \\
\hline $\mathrm{b}$ & Saving in 50 years & $\$ 75,131.14$ & \\
\hline
\end{tabular}

Table 3. Saving in maintenance cost.

\begin{tabular}{llll}
\hline S. No & Description & With Controller & Without Controller \\
\hline 1 & Rated Life (Hours) & 100000 & 29990.83 \\
2 & Operating hours in 50 years & 0 & 100000 \\
3 & Rate of maintenance in 50 years & 108.9 & 219243.33 \\
4 & Maintenance Cost per lightening pole & $\$ 0.00$ & 108.9 \\
5 & Total Maintenance $\$$ & $\$ 21,780.00$ & $21,780.00$ \\
c & Saving in Maintenance in 50 years & \\
\hline
\end{tabular}

Table 4. Natural gas sales opportunity.

\begin{tabular}{|c|c|c|c|}
\hline S. No & Description & With Controller & Without Controller \\
\hline 1 & Annual Power consumption (kWh) & 4498.63 & 32850 \\
\hline 2 & Reduction in Power Consumption (kWh) & 28351.38 & \\
\hline 3 & Annual Natural Gas Sale Opportunity & $\$ 1,587.68$ & \\
\hline $\mathrm{d}$ & Natural Gas Sale Opportunity in 50 years & $\$ 79,383.85$ & \\
\hline
\end{tabular}


Table 5. Saving in Pollution.

\begin{tabular}{llll}
\hline S. No & Description & With Controller & Without Controller \\
\hline 1 & Annual Power Consumption $(\mathrm{kWh})$ & 4498.625 \\
2 & Power Consumption in 50 years $(\mathrm{kWh})$ & 224931.25 \\
3 & Annual Saving in Pollution & $\$ 1,694.2752$ \\
$\mathrm{e}$ & Saving in Pollution in 50 years & $\$ 84,713.76$ \\
\hline
\end{tabular}

Table 6. Net Saving analysis in 50 years.

\begin{tabular}{lll}
\hline a & Initial Investment & $\$ 26,770.28$ \\
b & Saving in Energy & $\$ 75,131.14$ \\
c & Saving in Maintenance & $\$ 21,780.00$ \\
d & Saving in Natural Gas & $\$ 79,383.85$ \\
e & Saving in Pollution & $\$ 84,713.76$ \\
F & Total Saving Cost & $\$ 234,238.47$ \\
$\mathrm{f}$ & Total Saving in 50 years & $\$ 234,238.47$ \\
\hline
\end{tabular}

\subsection{Indirect Benefits}

In indirect saving, two benefits of implementing the lighting system will be drawn into attention [12].

\subsubsection{Natural Gas Sales Opportunity}

First benefit is natural gas sales opportunity (Table 4) gained from reduction of the power consumption calculated based on below formula (1).

\subsubsection{Saving in Pollution}

Second benefit is the cost saving due to reduction of the $\mathrm{CO}_{2}$ emission, hence less pollution. (Table 5) calculate the related saving based on formula (2).

\subsubsection{Total Saving Analysis}

Table 6 summaries the calculations in direct and indirect savings. It is obvious that total saving for only $4 \mathrm{~km}$ road in 50 years is $\$ 234,238.47$.

\subsection{Discussion}

To sum up, huge amount of money can be saved if such project is implemented. In case that this system is applied to only $100 \mathrm{~km}$ road. Total annual saving becomes about $\$ 117,119.24$; total saving in 50 years becomes $\$ 5,855,961.75$ It means that such system saves huge amount of energy and hence expenditure that can be utilized in other projects' finance. From is discussion, it is also possible to calculates the "Saving Norm" for the proposed system to be $\$ 1,171.19 / \mathrm{km} /$ Year.

\section{Conclusion}

The paper provided automation design for the illumination system for low traffic roads in order to solve the problem of operating the road not only economically but also safely. Image recognition techniques was used based on identification of vehicle number-plate to recognize the objects, is it vehicles or not? Image recognition algorithm was tested on different objects. The result from test has proved the validity of the algorithm that is used to detect different types of vehicle. Comprehensive techno-economic analysis was carried out and the result showed a great saving can be achieved, and hence, "Saving Norm" of $\$ 1,171.19 / \mathrm{km} /$ Year was calculated for the proposed system too. This "Saving Norm" is a good index to supports project management for both project decision makers and for cash-flow controllers. The calculated value of this "Saving Norm" index encourages the implementation of this technique in any Low-Traffic Long-Roads. This index is expected to be much higher, and hence more cost saving, in case road lighting uses HID bulbs instead of LED bulbs.

\section{Acknowledgements}

I would like to thank Nazrin Dolxanova for her effort in the survey and collecting information.

\section{References}

[1] Cornell University. "What is the traffic volume cut off between high-volume and low volume?" Cornell Local Roads Program. https://www.clrp.cornell.edu/q-a/151-low-volume.html\#: :text $=1 \% 2 \mathrm{C} 000 \% 20$ vehicles $\% 20$ per $\% 20$ day $\% 20$ is, upon $\% 20$ conte $\mathrm{xt} \% 20$ including\%20functional $\% 20$ classification.

[2] P. V. K. Bhangdiya, "Low Power Consumption of LED Street Light," International Conference on Global Trends in Signal Processing, Information Computing and Communication, 2016.

[3] Noor Lina Ramli, N. Mohd Yamin, "Implementation of passive infrared sensor in street lighting automation system," ARPN Journal of Engineering and Applied Sciences, 2015.

[4] Sindhu. A. M, Jerin George, Sumit Roy, Chandra J, "Smart Streetlight Using IR Sensors," IOSR Journal of Mobile Computing \& Application (IOSR-JMCA), 2016.

[5] Ms. M. Kokilavani, Dr. A. Malathi "Smart Street Lighting System using IoT," International Journal of Advanced Research in Applied Science and Technology ISSN, 2017.

[6] Faiz Ansari, Saima Khan, Aakash Jaiswar, Pooja Khiste, Milind Nemade, "Zigbee Based Smart Street Light Control System," International Journal of Innovative Research in Science, Engineering and Technology, 2016.

[7] Aman Kumar Akash Oraon Siddharth Agarwal, "Intelligent Street Lighting System Using Gsm," International Journal of Engineering Science Invention, 2013. 
[8] D. SA. S. Rajasri, "Automatic streel light control system using wireless sensor networks," in IEEE international Conference on Power, Control, Signal and Instrumentation Engineering, 2017.

[9] Muhammad M. A. S. Mahmoud, "Typical Economic Model for Calculating the Saving Norm of Replacement HPS Street Lighting by LED Fixtures in Access Road of Gas Production Company at GCC", 5th International Conference on Electrical and Electronic Engineering (ICEEE), 2018.

[10] Tvilight, "Energy savings through dynamic dimming on the S100 in Nijmegen", Intelligent Roadway Lighting. https://www.tvilight.com/2016/10/18/case-study-public-roadw ays/.

[11] Intelilight, "Intelligent Street Lighting," https://intelilight.eu/.

[12] Muhammad M. A. S. Mahmoud "Economic Model for Calculating the Global Saving Norm of Replacement High-Intensity Discharge Lamps with LED Lamp in Oil and Gas Plant”, IEEE 61st International Scientific Conference on Power and Electrical Engineering of Riga Technical University (RTUCON) 2020.

[13] Reham Faour, Bassel Shanwar, Nizar Zarka, "Recognition of Vehicle Numberplate using MATLAB", DOI: 10.13140/RG.2.1.1459.8640, 2016.

[14] M. K. B. Ashan and N. G. J. Dias, Recognition of Vehicle License Plates using MATLAB", European International Journal of Science and Technology Vol. 5 No. 6, August, 2016.
[15] Jing-Ming Guo; Chih-Hsien Hsia; KokSheik Wong and others, Nighttime Vehicle Lamp Detection and Tracking With Adaptive Mask Training", IEEE Transactions on Vehicular Technology, Vol. 65, Issue: 6, June 2016.

[16] Hazim Hamza Supervisor, Paul WhelanNight, "Time Car Recognition Using MATLAB”, M-Eng in Electronic Systems 2013.

[17] Pacificlamp.com, https://pacificlamp.com/street-light.asp.

[18] Republic, http://www.tariffcouncil.gov.az/?/az/content/70/.

[19] A. A. Circuits, "Low-Cost Programmable Logic Controllers for the Frugal Engineer," https://www.allaboutcircuits.com/news/low-cost-programmabl e-logic-controllers-for-the-frugal-engineer/.

[20] Alibaba, "Signal 2cores twisted pair armoured rs485 cable price,"

https://www.alibaba.com/product-detail/Signal-2cores-twisted -pair-armoured-rs485 62193928910.html?spm=a2700.772485 7.normalList. $9.38 \mathrm{~b} 06 \overline{4} 25 \mathrm{~h} 3 \mathrm{AeQA} \& \mathrm{~s}=\mathrm{p}$.

[21] Muhammad M. A. S. Mahmoud, Detection of single Line-to-Ground Faults Through Impedance in Mesh Distribution Network, IEEE Modern Electrical Power System MEPS15, Wroclaw 2015.

[22] Muhammad M. A. S. Mahmoud Review of Fuzzy and ANN Fault Location Methods for Distribution Power System in Oil and Gas Sectors, IFAC, Elsevier 2018.

\section{Biography}

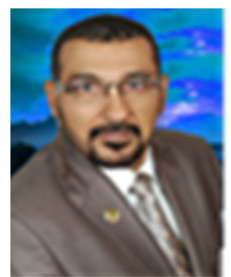

Muhammad M. A. S. Mahmoud, Egyptian, Received the B.S. degree in Electrical Engineering from Cairo University and the M.Sc. degree from Kuwait University. First Ph.D. degree from Transilvania University of Brasov, Romania in IT and Computer. Second PhD Degree in Electrical Power system and Machine, Cairo Univ. Egypt. He occupies a position of Professor in Process Automation Engineering Department, Baku Higher Oi School, Azerbaijan. His current research interests in Fuzzy and Artificial Neural Network Techniques application include power delivery, protection reliability, control, safety, building automation, smart city, and energy management. Prof. Dr. Muhammad is IEEE Senior Member (SM) since 2001 and TFS -IEEE Reviewer 2016.

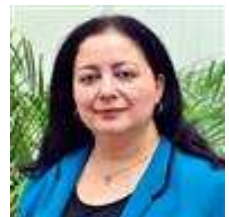

Leyla Muradkhanli has received BSc/MSc degrees in Control Systems from Azerbaijan Institute of Oil and Chemistry and a PhD in Management Information Systems from the Azerbaijan State Oil Academy. She also received an MSc in Energy Management from BI Norwegian School of Management, Norway. She is Associate Professor in Process Automation Engineering Department, Baku Higher Oi School, Azerbaijan. Her research interests include Artificial Intelligence, Machine Learning, Data Science, Energy Management and Alternative Technologies 